\title{
Cotidiano
}

\section{ÉTICA E EDUCAÇÃo}

Carlos Alberto Tolovi (1)

\begin{abstract}
Resumo
Atualmente nós podemos afirmar que esta primeira década do século XXI está sendo marcada por diversas formas de contradições que desafiam o ser humano na perspectiva da sociabilidade. $\mathrm{O}$ avanço tecnológico, cada vez mais rápido e surpreendente, não se traduz em justiça social (não diminui o grande e vergonhoso fosso entre ricos e pobres). $\mathrm{O}$ desenvolvimento científico não se traduz em qualidade de vida para todos, mas no privilégio dos poucos consumidores de elite. A quantidade e a qualidade das leis, produzidas por especialistas, a partir da necessidade coletiva, não se traduz em garantia de justiça humana e muito menos em segurança pública. A crise da moral não se transformou na afirmação da ética. Afinal de contas, mesmo vivendo num "mundo informatizado" nós podemos perceber que a informação dificilmente se transforma em conhecimento; e que o conhecimento dificilmente se transforma em sabedoria. E é nesse contexto que está inserida a crise da educação. Além da falta de investimentos financeiros nós vivemos a falta de uma relação dialógica e dialética que possa produzir valores humanos e que, por sua vez, possam enriquecer as relações intersubjetivas, na objetiva perspectiva da corresponsabilidade social.
\end{abstract}

Palavras-Chave: Ética; Moral; Construção humana; Liberdade, Coerência, Intencionalidade, Reflexão, Sabedoria. 


\section{Preâmbulo}

Nos dias de hoje o tema da ética tornou-se necessidade emergente como elemento de reflexão em todo o mundo. Diante da realidade do aquecimento global, trazendo a necessidade de se repensar a postura do ser humano frente ao planeta, nasce uma nova perspectiva: a de corresponsabilidade cósmica que só pode brotar a partir de uma nova visão de mundo. Fazer repensar o lugar e o papel do ser humano frente ao todo é papel da ética. E construir referenciais para um comportamento ético é papel da educação.

Em nosso país, onde vemos a corrupção cada vez mais entranhada ao tecido social, o tema da ética também se torna uma necessidade emergente. Atualmente é muito comum vermos instaurados Conselhos de Ética para o julgamento de atos de corrupção e decoro parlamentar; é muito comum ouvirmos falar em bioética, diante da polêmica pesquisa com células tronco, etc.. Contudo, o grande problema consiste em definir de fato os fundamentos da ética e a distinção entre ética e moral. No campo da política, por exemplo, é muito comum vermos parlamentares corruptos tomando assento nos Conselhos de Ética para julgarem seus colegas que foram denunciados pela mídia. É como se o grande problema fosse a evidência da corrupção, e não o ato de corromper.

Neste ensaio pretendemos oferecer uma provocação que tem como desafio a proposta de uma reflexão em busca dos fundamentos da ética. Mas, acima de tudo, pretendemos situar o desafio da ética como um desafio da educação. Defendemos que é nos espaços educativos que a ética deve ser cultivada como um referencial que só faz sentido de existir através de uma práxis humanista e libertadora.

\section{O Nascimento da Ética}

Quem somos nós? Como explicar o mundo onde estamos inseridos? Como explicar o caos e a ordem deste mundo?

Estas perguntas, antes mesmo de desafiarem a filosofia e a antropologia, sempre desafiaram o ser humano em sua existência. Afinal de contas, a emergência da consciência colocou o ser humano num nível diferenciado ao dos outros animais. Como afirma Manfredo Araújo de Oliveira, “o que o homem é nunca está decidido de uma vez para sempre, mas exatamente, em contraposição ao mundo animal, o homem revela-se como ser essencialmente aberto.” (OLIVEIRA, 1993: p.11-12) É justamente nesta perspectiva que encontra-se o 
desafio da humanidade: o nosso lugar de morada não é simplesmente dado, ele precisa ser construído; até as respostas com relação as nossas origens, ao sentido do nosso existir, ao que nos espera depois da morte, precisam ser construídas.

No princípio, os deuses, criados pelos próprios seres humanos, explicavam tudo. Os mitos explicavam como tudo passou a existir. A origem, a ordem e a finalidade eram definidas pelos mitos. Estes definiam também como deveria ser o comportamento humano, por meio da religião e das normas morais. E dentro dessa visão de mundo delimitada pelos mitos, cada ser humano tinha que se deparar com o seu próprio destino. O determinismo mítico marcava profundamente a visão de mundo da época. A narrativa de Édipo traduz bem a consmovisão desse tempo: quanto mais tentava fugir do destino, mais o ser humano ia de encontro à ele. Por meio dos deuses os seres humanos elaboravam respostas para todas as suas perguntas. Afinal de contas, diante da consciência, a falta de respostas pode gerar o caos. Contudo, o ser humano não suporta viver no caos. Sendo assim, por meio dos deuses, ele sempre elaborou respostas para as suas próprias perguntas. O mito, portanto, é a projeção humana que lhe abre as portas para o imaginário e a transcendência. Mas é também, e principalmente, uma forma de responder para si mesmo a questões que a razão não consegue explicar. Portanto, enquanto parece que os deuses explicam tudo, justificam tudo, definem tudo, é o ser humano que está delimitando e controlando o seu lugar de morada.

Diante da consciência nasce o desconhecido. Diante do desconhecido surge a possibilidade do caos. Para fugir do caos os seres humanos criam mitos e religiões com o objetivo de construírem (inconscientemente) suas próprias respostas. As respostas oferecem uma forma de ordenamento. A ordem corresponde ao cosmos. O cosmos é um lugar seguro pra morar. Portanto, o cosmos corresponde a uma extraordinária construção humana.

Nesta perspectiva, educar consiste em transmitir os conhecimentos pré-estabelecidos e assumidos pela tradição. Nesse contexto o educador assume o papel de narrador, explicando, justificando e conformando o educando na consmovisão tradicional. O educador é o mantenedor da ordem cósmica que corresponde à moral.

Num segundo momento, na perspectiva do desenvolvimento da cultura ocidental, alguns seres humanos começam a desbravar novos caminhos para explicar a origem de todas as coisas e a ordem do cosmos. Os primeiros filósofos iniciam uma revolução epstemológica. Na perspectiva consmocêntrica a Physis começa a ocupar o lugar dos deuses. O fundo eterno, de onde tudo emana, a partir de onde tudo ganha forma e se ordena, passa a se tornar uma alternativa que possibilitará explicações muito mais racionais. Contudo, o extraordinário ato de rebeldia contra os deus (sem se dar conta disso) foi a construção da polis. Esta não era 
apenas uma cidade-estado com organização independente, um lugar geográfico específico, mas era, essencialmente, a construção de um espaço ontológico. A partir desse momento o ser humano começa a perceber-se a si mesmo como um Ser criador. Apesar de estar buscando reproduzir a ordem do cosmos, criado, organizado e mantido pelos deuses, ele passa a assumir a criação de um espaço onde a ordem e a harmonia é sua própria tarefa. Não houve salto. Não houve ruptura. Os mitos aos poucos foram assumindo cada vez mais as formas humanas, com suas qualidades e seus defeitos. Com isso abriu-se uma nova porta para a humanidade.

Neste novo contexto o papel da educação e do educador também se transforma. O cosmos não é mais propriedade única e exclusiva dos deuses. A polis é um novo cosmos. E esta precisa ser governada pelos seres humanos, a partir de sua organização, suas escolhas. O nascimento da democracia exigia uma postura de corresponsabilidade diante de uma realidade muito mais complexa e racional. Com isso era preciso que o educador ajudasse o educando a se preparar para assumir, de forma corresponsável, o destino da polis. O educador precisava ajudar o educando a construir argumentos lógicos e racionais que pudessem convencer nas grandes assembléias. Afinal de contas, entendido como sábio, o educador era aquele que preparava os seus alunos para intervirem na realidade política e social em que eles estavam inseridos. É nesse contexto em que surgem os sofistas com a clássica afirmação: “o homem é a medida de todas as coisas". Portando, a verdade depende da convenção; e a convenção depende da força do argumento.

Essa afirmação abre as portas para uma nova revolução epstemológica, para uma nova concepção de mundo. Agora o destino humano encontra-se em suas próprias mãos. E a educação é, por excelência, o lugar de preparação para que esse protagonismo aconteça.

\section{A Ética como Construção Humana}

Agora a polis é construção humana, responsabilidade humana. É um lugar seguro pra morar, organizado pelas leis, definidas pelos próprios homens. Enfim, a polis é a possibilidade de uma vida boa e feliz sem a completa dependência dos deuses. É certo que eles ainda colaboram para a ordem, mas não determinam tudo. Eles ainda "explicam" a origem e a ordem da natureza cósmica, mas não exercem mais o completo domínio sobre a natureza e a liberdade humana. 
Contudo, um novo desafio se apresenta: para manter a ordem é preciso controlar os impulsos e desejos como fonte de rivalidade entre os seres humanos. O desejo mimético ${ }^{1}$ sempre colocou em risco a existência humana. Isso explica porque sempre se fez necessário a intervenção dos deuses e da religião por meio de normas morais e dogmas doutrinários. Além do Estado, essa foi uma das formas que os seres humanos encontraram para a manutenção da ordem na vida coletiva.

Mas, na polis, construída por "mãos" humanas, regulada pela razão - por meio das leis - havia a necessidade de algo mais. As leis, elaboradas pelos cidadãos, passaram a representar um auxílio efetivo e eficiente na busca da superação do caos. Contudo, ao despertar para a potencialidade da razão, os pensadores gregos perceberam que ela poderia se tornar uma grande aliada na tentativa de garantir a harmonia nas relações humanas, tomando por base a dimensão moral.

Surgia então uma nova necessidade: a construção de valores norteados pela reflexão na perspectiva da intersubjetividade. O desafio agora era construir um mecanismo regulador que não representasse uma imposição externa dos deuses ou da pura convenção coletiva. Assim foi lançado o desafio da ética como construção humana. Era preciso encarar a elaboração de valores que deveriam se transformar em princípios norteadores da conduta humana, tendo como base a relação de alteridade (onde o outro é sujeito de direitos, dignidade e possibilidades, iguais a mim). Nessa perpectiva, não fazer mal ao outro não seria mais exigência dos deuses, mas uma exigência da razão. Portanto, a reflexão torna-se a mediação necessária para o agir bem. Com isso, o ser humano deixa de ser objeto passivo das normas pré-estabelecidas. Ele passa a ter de assumir, de forma autônoma, os seus próprios princípios.

Mas então a ética seria uma atitude da razão e da consciência individual?

Os gregos, provocados por Sócrates e Aristóteles, sabiam que a construção da virtude (areté) só era possível na perspectiva da dimensão relacional. Aristóteles, em "Ética a Nicomaco", defende que a virtude pode ser definida como a constante busca do ser humano em agir bem, tendo como referência os bons costumes e a razão. Mas para isso, faz-se necessário encontrar sempre a justa medida.

Podemos concluir então que a ética nasce da necessidade de se encontrar um dispositivo de emancipação humana, isto é, onde a consciência e a liberdade individuais se encontram com as necessidades coletivas, na busca da harmonia na dimensão inter-individual.

\footnotetext{
${ }^{1}$ Sobre este assunto Cfr. GIRARD, René. A violência e o Sagrado, São Paulo, Ed. Paz e Terra, 1990. 
Nesta perspectiva a educação tem papel fundamental. Isso porque, educar não se limita em informar, repassar conhecimentos construídos e acumulados por outros. Educação consiste, essencialmente, em relação. E se essa relação for de alteridade, onde o educador reconhece o educando como sujeito de forma integral, onde a comunicação se torna dialógica, despertando o exercício da razão autônoma, na perspectiva da dialética, então o ambiente será propício para a construção de referenciais norteadores de uma postura ética frente as mais diversas situações do dia-a-dia. Nesse contexto, o exercício da ética corresponde ao exercício da cidadania. Portanto, o papel da escola não é formar cidadãos mas, por meio de uma relação educativa, despertar na consciência valores norteadores de ações práticas sempre permeadas por uma reflexão lógica na busca da coerência.

\section{A Diferença entre Ética e Moral}

Depois dos gregos a nossa cultura passa pela romanização e, posteriormente, será profundamente marcada pelo cristianismo, a partir da institucionalização cada vez mais forte do catolicismo. Nesse momento o dogma acaba se tornando a base de uma moral religiosa que irá definir a visão de mundo e as relações sociais de diversas gerações. Em nome de Deus e da moral a instituição "Igreja Católica" afirma o seu poder. Em nome de Deus as relações hierárquicas são fortalecidas, a submissão é cristalizada, a definição do bem e do mal fortalece as relações assimétricas de poder entre homem e mulher, entre o branco e o negro, etc.. Neste novo contexto a moral religiosa é colocada como o único paradigma que pode nortear as relações humanas.

Contudo, a antítese produzida no renascimento, tentando resgatar a autonomia do ser humano e da razão, em detrimento do teocentrismo e do dogmatismo, ganha força na modernidade. E nesse momento, a retomada da incrível revolução epstemológica que acontece na Grécia antiga torna-se fundamental. E o caminho para resgatar a autonomia humana em busca da maioridade desponta como sendo a definição da ética como forma de extrapolar os limites da moral.

Contudo, esse processe de distanciamento de uma visão moral delimitada por preceitos religiosos não se deu de forma tranqüila. Ainda hoje é muito comum perceber que, no universo do cotidiano, há grande confusão entre ética e moral. Inclusive nos espaços acadêmicos essa confusão perpassa muitas discussões. Mas não é por acaso. A palavra ética, por exemplo, é de origem grega (ETHIKE), que se refere ao costume. A palavra moral é de 
origem latina (MORIS), e também se refere à costume. E diante de toda a tradição dos pensadores que mais influenciaram os debates sobre a ética, não se percebe a preocupação em esclarecer sobre a devida distinção entre esta e a moral.

Para esclarecermos bem essa questão, precisamos retomar o raciocínio anterior. Enquanto o mito explicava a origem, o destino e a finalidade de todas as coisas, o ser humano inserido nessa lógica determinista assumia também as normas de conduta pré-estabelecidas pelos deuses e determinadas pela coletividade, no limite de sua cultura. A vontade dos deuses, geralmente assumida pelas instituições religiosas e familiares ${ }^{2}$ virava costume e garantia a ordem. Nesta perspectiva, para evitar o caos que poderia ser desencadeado pelo desejo mimético, para oferecer segurança e garantir "vida boa", bastava ao ser humano a adesão sem a necessidade da reflexão ou da fundamentação. Com isso, o ETHOS (lugar de morada humana) estava garantido. Portanto, para agir moralmente, bastava situar-se dentro desta ordem pré-estabelecida.

Nesta perspectiva podemos afirmar que a moral refere-se à valores que se transformam em normas de conduta, construídas por um determinado grupo social. Estes valores e estas normas, assumidos socialmente, se impõem ao indivíduo, como algo construído antes dele e que não cabe questionar. Sendo assim, uma ação moral é determinada pelo costume, pelo medo da reação da família ou da sociedade, pelo medo da reação da divindade, pelo receio da repressão ou da rejeição.

$\mathrm{Na}$ perspectiva do senso comum, quando um professor, antes mesmo de chegar em sala de aula, recebe a informação de que nesta há um grupo de alunos "danados" e que, por isso, ele precisa chegar "colocando moral", já podemos definir um dos aspectos fundamentais deste conceito. Neste sentido moral serve como um mecanismo de ordenamento, imposto por alguém que faz uso da autoridade. Neste mesmo sentido é muito comum ouvirmos a afirmação que determinados pais não têm mais moral sobre os filhos - no sentido do controle sobre estes.

Por outro lado, também na perspectiva do senso comum, podemos entender a moral como valores pré-estabelecidos, cristalizados coletivamente pelo costume, a partir de uma linguagem simbólica. Assim, em nossa cultura, por exemplo, podemos perceber a supervalorização do branco em detrimento do negro; a super-valorização do masculino, em detrimento do feminino; a super-valorização do divino, em detrimento do humano. Podemos dizer que, deste ponto de vista, alguns valores elaborados por uma determinada cultura

\footnotetext{
2 . Sobre este assunto cfr. Carlos Cirne-Lima, em sua obra: Dialética para Principiantes, pp.169-171. 
ajudam a sustentar o racismo, o machismo, enfim, uma relação humana de desigualdade. Nesta perspectiva é que a mulher flagrada em "adultério" poderia e pode ser condenada; os negros, escravizados; os índios, catequizados e dizimados. É a perspectiva da aculturação e da colonização, onde ocorre a imposição e sobreposição dos valores pré-estabelecidos por um determinado grupo social, nos limites de sua visão de mundo.

Em suma, podemos afirmar que a moral pode ser definida como normas de conduta que brotam a partir de valores que definem a visão de mundo e o comportamento de um determinado grupo social nos limites de uma cultura. ${ }^{3}$ Portanto, o que é definido como valores morais em uma sociedade pode não ser em outra.

Neste contexto o papel da educação é garantir a manutenção da ordem social. Os pais exigem que os filhos assumam os mesmos valores morais para serem considerados "filhos educados". Os professores preparam seus alunos para o que eles definem como "mundo lá fora”. Um mundo cheio de imoralidades, seduções, sem religião, etc.. O bom educando é o que reproduz, de forma disciplinada, as informações recebidas e assume para si os valores pré-estabelecidos pelos mantenedores da ordem. A autonomia não é estimulada. Perguntar pode significar um desrespeito aos educadores ou aos pais.

Por outro lado, para definirmos a ética, como no caso da moral, também devemos retomar um raciocínio anterior referente às suas origens.

A ética nasce num contexto de grande revolução humana do ponto de vista epstemológico. Com a construção da polis os seres humanos assumem a responsabilidade que antes era dedicada aos deuses: zelar pela ordem cosmológica na perspectiva das relações interindividuais, tendo o ser humano como a maior referência. Contudo, os gregos perceberam que as normas e costumes religiosos, que as leis da polis e que a democracia não eram o suficiente para garantir a harmonia. Eles sentiram a necessidade da construção de valores, por meio da educação, que servissem como princípios norteadores da relação. E a grande diferença é que esses princípios seriam norteados pela razão.

Mas se por um lado nós podemos definir a ética como filha da razão filosófica, por outro, não podemos pensar que esta seja limitada pela pura racionalidade. Afinal de contas, como afirma Manfredo Araújo de Oliveira ${ }^{4}$ ela só faz sentido na dimensão da sociabilidade.

Nesta perspectiva podemos começar definindo a ética como um instrumento de reflexão que tem no exercício da razão a fonte norteadora das escolhas e atitudes que, de

\footnotetext{
${ }^{3}$ Cfr. Roque de Barros Laraia. Cultura, Um Conceito Antropológico. Pp.67-79.

${ }^{4}$ Sobre este assunto Cfr. OLIVEIRA, Manfredo Araújo de. Ética e Sociabilidade, São Paulo, Col. Filosofia n. $25^{\text {a }}$, Ed. Loyola, 1993.
} 
forma direta ou indireta, relaciona-se com a vida humana. Assim, cuidar bem da natureza, na perspectiva da corresponsabilidade social e ambiental, deve ser fruto de uma nova consciência, produzida por uma nova reflexão. Um recente exercício racional que leva o ser humano a olhar de forma diferente para o planeta em que habita. Esta nova reflexão é papel fundamental da educação.

Além disso, a ética também deve ser entendida como instrumento de reflexão filosófica que analisa criticamente os valores morais. Sendo assim, a ética não se limita à normas de conduta. Também não é refém dos limites de uma determinada cultura. Não se baseia na adesão norteada pelo costume ou pela tradição. Mesmo porque, em nossa cultura sempre foi costume olhar para o divino como um ser masculino. Sempre foi costume olhar para o feminino como o "sexo frágil". Sempre foi costume olhar para o branco como o belo e/ou sagrado. Portanto, por meio de uma reflexão ética, é papel da educação desconstruir estes antigos paradigmas.

Por fim, a ética não se baseia em normas, mas em princípios; não se baseia na tradição, mas na reflexão; não se baseia em valores pré-estabelecidos que não exigem fundamentação, mas em valores norteadores que são assumidos como base para garantir a harmonia sem eliminar a autonomia. Portanto, se a educação se propõe ser libertadora ela precisa assumir a dimensão de relação, tendo em vista a construção de valores que possibilitem o fortalecimento do bom caráter na perspectiva das relações sociais. São valores que, depois de serem construídos na dimensão da razão e da subjetividade humana, devem extrapolar para os limites práticos e concretos das ações interindividuais.

\section{Alguns Princípios Norteadores para uma Ação Ética}

Se anteriormente nós afirmamos que uma ação moral é a que obedece à normas de conduta que não exigem reflexão, mas apenas adesão; se afirmamos também que a ética, diferentemente da moral, exige fundamentação, por meio do exercício da razão, norteado por princípios; devemos esclarecer agora que princípios são estes.

\section{a) Princípio da Liberdade}

O ser humano é, essencialmente, um ser de vontade. Contudo, diferentemente dos outros animais, ele precisa relacionar a sua vontade à dimensão de liberdade. Afinal de contas, 
a liberdade, na perspectiva do livre-arbítrio, é filha da consciência racional. Mesmo porque, se nascemos numa "caverna" onde as normas morais pré-estabelecidas correspondem às paredes que delimitam a nossa visão de mundo (na perspectiva de Platão), dentro desta vamos tomando consciência de como devemos agir, assumindo a idéia de bem e de mal como referência. Portanto, se temos consciência de como devemos agir, nos deparamos automaticamente com a questão da liberdade. Como afirma Kant, "nós adquirimos a consciência da liberdade exatamente porque antes de tudo temos consciência do dever". (REALE, 1990: pg.914)

Se nossa ação não pudesse oscilar entre o bem e o mal, entre o certo e o errado, não poderíamos nos considerar livres. É por isso que, no mito de origem que mais influenciou a nossa cultura, o narrador coloca no centro do paraíso a árvore que produz frutos do bem e do mal. Contudo, não bastaria colocar a árvore se não houvesse a ordem proibindo o acesso à esse fruto (Gn 2, 4-17)). Diante da ordem, do limite estabelecido pelo divino, emerge a consciência. E diante da consciência a possibilidade de escolha. Diante da possibilidade de escolha, a liberdade atribuída à todos os seres racionais. Por este princípio podemos até afirmar que Eva agiu eticamente buscando superar as contradições da narrativa.

Portanto, uma ação só pode ser considerada ética se ela for norteada pelo princípio da liberdade incondicional - tomando como base o lire-arbítrio. Assim, uma coisa é o motorista parar diante da faixa de pedestre para que as pessoas passem de um lado para o outro sob os olhares atentos de um guarda de trânsito. Outra coisa é o motorista parar sem que haja nenhuma forma de coerção externa que o obrigue, apenas por uma questão de consciência do dever ser. Uma coisa é a imposição de algo em sala de aula à base do medo da reação da professora que, com autoridade, garante a ordem. Outra coisa é a disciplina e a harmonia em sala de aula que brota do respeito conquistado e construído por uma relação de alteridade.

Se a educação quer levar o aluno ao exercício da cidadania, então precisa leva-lo a assumir, de forma consciente e livre, as suas escolhas como sujeito histórico. Mesmo porque, a liberdade desemboca na responsabilidade. E esta colabora para a construção da autonomia, em busca da sabedoria.

\section{b) Princípio da Não-contradição - Coerência}

É importante saber que o princípio da liberdade, por si só, não é suficiente para definir uma ação como sendo ética. Podemos afirmar que um outro grande desafio da ética consiste 
na construção do dever ser universal. Em outras palavras podemos resumir que a universalidade representa a grande utopia ${ }^{5}$ da ética.

Para Carlos Cirne-Lima o dever-ser universal consiste na não contradição, que corresponde ao princípio da coerência (CIRNE-LIMA, 1997; p.180-182). É uma forma de traduzir o imperativo categórico de Kant: “age só segundo a máxima tal que possas ao mesmo tempo querer que ela se torne lei universal" (KANT, 1785). ${ }^{6}$

Aqui, máxima deve ser entendido como um princípio subjetivo. Assim sendo, nossas ações práticas devem obedecer à princípios subjetivos universais. Mas, como isso seria possível?

É nesta perspectiva que a ética extrapola os limites da moral. Como já afirmamos anteriormente, enquanto a conduta moral obedece à normas pré-estabelecidas nos limites da visão de mundo de uma determinada cultura, a ética deve obedecer à princípios que exigem reflexão para superar a contradição, independente dos valores culturais de um determinado grupo social. Portando, desejar ao outro o que não queremos para nós mesmos, consiste numa contradição e numa incoerência. Assim também julgar o outro com medidas que não aceitamos que sejam atribuídas à nós mesmos consiste na mesma contradição. É por isso que, diante da prostituta que estava para ser apedrejada em nome da lei de Moisés, Jesus propõe uma reflexão de caráter universal: "quem não tiver pecado que atire a primeira pedra" (Jo 8,111)). Se a lei de Moisés respondia à necessidade de uma sociedade machista que, para manter a ordem, deveria subjugar os direitos da mulher, o imperativo categórico de Jesus provocou a reflexão a partir de um princípio universal: a não contradição (aqui está a prostituta, mas, onde ficou o prostituto? Alguém se prostitui sozinho?).

Se para os fariseus, aderir às normas religiosas de seu tempo correspondia a uma ação moral, para Jesus essa adesão sem reflexão provocava uma contradição que, por sua vez resultava numa ação incoerente e injusta.

Por serem éticos, tanto Sócrates como Jesus foram condenados em nome da moral de um determinado grupo social, situado historicamente nos limites da visão de mundo de uma determinada cultura.

É muito comum, nas instituições educacionais o aluno não ser estimulado a pensar livremente, a construir o seu próprio conhecimento, a assumir seus argumentos. Aliás, num

\footnotetext{
${ }^{5}$ Utopia aqui é entendida como algo distinto de sonho. Isso porque, podemos sonhar com os "olhos fechados", com os "pés fora do chão", desconectadas da realidade. Por outro lado, podemos afirmar que os grandes revolucionários foram grandes utópicos: com os "pés no chão", "olhos abertos", mirando uma direção. E esse objetivo, para os revolucionários, tornou-se um desafio para a vida toda. Portanto, uma utopia é algo projetado como pleno, no futuro, mas tomado como referência concreta e prática para o presente.

${ }^{6}$ Cfr. PASCAL, Georges. Pensamento de Kant, Petrópolis, 3. ed, Ed. Vozes, 1990.
} 
universo onde o aluno só aprende a reproduzir, ele vai ficando cada vez mais inseguro para produzir um raciocínio lógico e autônomo, fazer sua própria hermenêutica, defender suas próprias idéias e relacionar a lógica de seu raciocínio com sua prática diária. Entender que os cuidados com o planeta passa pela responsabilidade de cada ser humano, pode significar uma tomada de consciência que fará diferença nas atitudes práticas do aluno. Como afirma os parâmetros Curriculares: “A escola deve ser o lugar onde os valores morais são pensados, refletidos, e não meramente impostos ou frutos do hábito". (PCNs, Vol. 8, pg 81)

\section{c) Intencionalidade}

Tomando por base o fato de que ética é uma construção humana que só faz sentido na perspectiva da sociabilidade, temos que levar em conta também a dimensão da intersubjetividade. A questão aqui é entender o que define de fato as minhas atitudes, as minhas escolhas, enfim, a minha ação. Afinal de contas, como nossa vida é interligada com outras vidas, o nosso ser, interligado com outros seres, o outro, entendido como um Tu, é condição sine qua non para a existência da ética. Sendo assim, sempre que o outro for tomado como um meio para atingir um fim que não é ele mesmo, a ação poderá ser considerada antiética.

Como afirma Martin Buber, "aquele que diz Tu não tem coisa alguma por objeto. Pois, onde há uma coisa há também outra coisa. (...) Quem diz Tu não possui coisa alguma, não possui nada. Ele permanece em relação”. (BUBER, 1974; p.9)

Portanto, sempre que a minha intenção for usar o outro como objeto para atingir um fim que consiste na realização dos meus próprios desejos, então esta ação não poderá ser considerada como ética.

Nesta perspectiva podemos afirmar que, uma coisa é buscar no outro a realização dos meus desejos sexuais; outra coisa é realizar com o outro a satisfação dos nossos desejos. Num caso houve a relação entre um sujeito e um objeto, no outro, uma relação dialógica que obedece a um dos princípios da ética. Uma coisa consiste em dar uma esmola para agradar a Deus, tendo em vista alcançar a salvação; outra coisa é interagir com o necessitado buscando fazer com que ele assuma a condição de sujeito histórico, resgatando a sua dignidade. Num caso o necessitado é objeto mediador de minha relação com Deus, tendo em vista a minha salvação. No outro ele é um sujeito de reciprocidade. Até os partidos de esquerda que propõem uma revolução socialista caem nesta cilada: se não conseguem dialogar com os empobrecidos, com as vítimas de uma sociedade desigual e injusta, também não conseguem 
transformar a realidade com eles. Então, agem e lutam por eles. Os injustiçados continuam na condição de objetos passivos.

Trazendo para o campo educacional podemos perguntar: quem é o aluno para o profissional da educação na relação com este em sala de aula?

É nessa dimensão que podemos distinguir a diferença entre o que chamamos de professor para o educador. O professor está preocupado em ensinar, o educador preocupa-se em educar. Mas, qual seria a diferença básica? Enquanto o professor preocupa-se apenas em repassar conteúdo, o educador preocupa-se também com a dimensão de valores na perspectiva da relação. Enquanto o professor preocupa-se com o fato do aluno armazenar o máximo possível de informações, o educador procura, a partir destas, provocar reflexões. Enquanto para o primeiro o aluno é objeto que justifica a sua profissão, o seu salário, garantindo a sua sobrevivência, para o segundo o aluno é sujeito de relação que motiva a sua realização profissional e pessoal. Somente neste segundo caso a educação poderá produzir ética.

\section{d) Reflexão}

Uma ação, para ser considerada ética, precisa passar pelo crivo da reflexão. Mesmo porque, como posso saber se uma ação é coerente sem pensar sobre a mesma? O exercício da reflexão é um dos pontos de separação entre ética e moral.

Quando Kant fala sobre a razão teórica e a razão prática ele está sempre buscando uma conexão coerente entre os dois pontos. Essa coerência, que é exigência do princípio de nãocontradição, só pode ser entendida a partir do exercício da reflexão. Portanto, se hoje nasce uma nova consciência a partir de uma nova reflexão elaborada sobre o meio-ambiente, junto com essa consciência nasce também a exigência de novas atitudes, novas práticas. Com isso podemos afirmar que a ética situa-se no universo da práxis dialética, onde não dá pra separar o processo de alternância constante entre reflexão e prática.

Nesta perspectiva é que situa o maior desafio da educação. Tradicionalmente as instituições educacionais e profissionais da educação estão preocupados em dar conta do conteúdo pré-estabelecido. Contudo, no universo de repasse dos conteúdos (informações) geralmente não há preocupação com o exercício da reflexão na perspectiva da consciência crítica que ajuda no despertar do sujeito histórico. Com isso o ensino não desperta para o exercício da cidadania, que consiste na apráxis da politicidade; não provoca o aluno para os desafios da ética. Enfim, o sistema de ensino que não ajuda o aluno pensar, a refletir, também não pode oferecer um espaço de cultivo de relações éticas, na perspectiva da corresponsabilidade social, ambiental e universal. 


\section{Considerações Finais}

Quanto mais o ser humano toma consciência de seu papel no mundo onde está inserido, mais aumenta a necessidade de uma reflexão sobre a ética. Quanto mais o ser humano se torna capaz de intervir na vida e na morte, mais se faz necessário um debate sobre a ética. Quanto mais entendemos a nossa responsabilidade social, ambiental e universal, mais somos chamados a nos inserirmos no universo da ética. Quanto mais somos chamados a assumirmos a nossa politicidade, pelo exercício da cidadania, mais somos desafiados pelo contexto da ética. Mas o primeiro grande problema consiste no fato de que o estudo sobre a ética ainda não ganhou espaço suficiente nas instituições de ensino-aprendizagem. O segundo problema é ainda maior: ética não é para ser apenas compreendida academicamente, mas vivenciada no dia-a-dia das relações interindividuais. Como afirmamos anteriormente, educação consiste essencialmente em relação. E essa relação só pode ser ética se acontecer na dimensão da alteridade e da reciprocidade.

Atualmente é moda a afirmação de que o papel da Escola é formar cidadãos. Como se a instituição educativa pudesse oferecer a "forma" modeladora da cidadania. Contudo, através deste nosso ensaio nós afirmamos que o exercício da cidadania brota de uma consciência ética que serve de parâmetro norteador para uma prática coerente no constante exercício da reflexão (práxis), na perspectiva da liberdade e da autonomia.

Podemos concluir que educação consiste na relação que envolve construção do conhecimento e construção de valores. Nesse processo relacional e dialógico a informação poderá se transformar em conhecimento, e este poderá ser elevado ao nível da sabedoria (práxis do conhecimento). Portando, não basta conhecer, é preciso saber o que fazer com o conhecimento que se tem.

\section{Referências}

BUBER, Martin. Eu e Tu, Trad. Newton Aquiles Von Zuben, São Paulo, 2a ed., Ed. Moraes, 1974.

CIRNE-LIMA, Carlos. Dialética para Principiantes, Porto Alegre, Col. Filosofia n.48, 2a . ed., Ed. Edipucrs, 1997.

GIRARD, René. A Violência e o Sagrado, São Paulo, Ed. Paz e Terra, 1990. 
LARAIA, Roque de Barros. Cultura: Um conceito Antropológico, Rio de Janeiro, $19^{\mathrm{a}}$ ed., Ed. Jorge Zahar, 2006.

OLIVEIRA, Manfredo Araújo de. Ética e Sociabilidade, São Paulo, Col. Filosofia n. $25^{\mathrm{a}}$, Ed. Loyola, 1993.

Parâmetros Curriculares Nacionais. Apresentação dos Temas Transversais: Ética. Ministério da Educação. Secretaria da Educação Fundamental. 3ª ed., Brasília, 2001.

PASCAL, Georges. Pensamento de Kant, Petrópolis, 3. ed, Ed. Vozes, 1990.

REALE, Giovanni \& ANTISERI, Dário. História da Filosofia. Do humanismo a Kant. $4^{\mathrm{a}}$ ed., Vol. 2, Ed. Paulus, 1990.

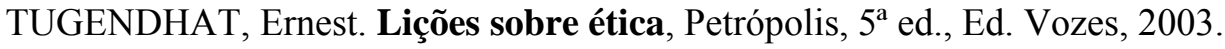

VV.AA. Ética em Três Dimensões, Fortaleza, Ed. Brasil Tropical, 2000.

\section{Sobre o autor:}

(1) Carlos Alberto Tolovi é Filósofo e Professor da Universidade Regional do Cariri - URCA. E-mail: ctolovi@yahoo.com.br 